\title{
Accuracy and bias of visual estimates of numbers, size structure and biomass of a coral reef fish
}

\author{
J. St. John ${ }^{1}$, G. R. Russ ${ }^{1}$, W. Gladstone ${ }^{2, *}$ \\ ${ }^{1}$ Department of Marine Biology, James Cook University, Townsville, Queensland 4812, Australia \\ ${ }^{2}$ School of Biological Sciences, F07, University of Sydney, Sydney, NSW 2006, Australia
}

\begin{abstract}
Accuracy and bias of visual estimates of the number, size structure and biomass of juveniles of a small coral reef fish, Salarias fasciatus, were examined on 10 artificial patch reefs at One Tree Reef, Great Barrier Reef. Visual estimates of the number and length of fish were made by 3 observers for 3 different durations $(5,10$ and $15 \mathrm{~min}$ ) at each reef. These estimates were compared to measurements obtained from subsequent destructive sampling of reefs $198.5 \%$ of fish collected from all reefs). An increase in census period does not continue to improve the accuracy of the estimates of numbers of fish. The accuracy of the 10 min census did not differ significantly from the 15 min census, although it was significantly higher than the 5 min census. Also, observers had unique biases for specific size-classes when estimating the size structure of the population. Biomass was estimated from the visual censuses of one observer, using a length-weight relationship, and compared to a known biomass from subsequent destructive collections. The mean accuracy of the biomass estimate derived from visual estimates of lengths was $72.3 \%$. This level of accuracy was obtained when the length-weight relationship was good $\left(r^{2}=0.97\right)$ and the estimates of lengths of each size-class (mean accuracy $=86 \%$, pooled for observer, times and sites) and the estimate of numbers (mean accuracy $=91.6 \%$ for the $10 \mathrm{~min}$ census) both had high levels of accuracy. But such high accuracies may not be expected for censuses of larger mobile species. The use of visual censuses to estimate the biomass of such fish populations are likely to be subject to greater inaccuracy. Most of the error in the visual estimates of biomass was explained by the inaccuracies of estimating the length of fish visually. Categorising fish into $5 \mathrm{~mm}$ sizeclasses or using a length-weight relationship to convert length to biomass did not significantly affect the accuracy of the estimates.
\end{abstract}

\section{INTRODUCTION}

Techniques of visual census are non-destructive and generally cost-efficient methods of estimating population size. Visual censuses have become an important method of determining the distribution and abundance of both coral and temperate rocky reef fishes. These methods are reviewed by Sale (1980a) and Thresher \& Gunn (1986). Ecologists working on reef fishes usually have been concerned only with density estimates of populations even though the size structure of fish populations has important ecological consequences. In fish, size is directly related to fecundity (Alm 1959) and the body weight of individuals within a species can span 4 or more orders of magnitude (Werner \& Gilliam 1984). The size of the individual is responsible for

- Present address: Great Barrier Reef Marine Park Authority, PO Box 1379, Townsville, Queensland 4810, Australia differences in levels of interspecific competition, predation, emigration and resource use (Jones 1987, Shulman \& Ogden 1987). Thus, estimation of size structure and biomass is an important goal in ecological studies of reef fish.

In reef fisheries, the use of visual census techniques to survey relative (GBRMPA 1979, Munro 1983, Bell et al. 1985) and more recently absolute (McCormick \& Choat 1987) population density and biomass has been recognised. Visual censuses have been used to determine the size structure of populations of coral reef fishes and make estimates of their biomass and standing stocks (e.g. Harmelin-Vivien \& Bouchon-Navaro 1981, Russ 1985, Bellwood \& Alcala 1988, Kulbicki 1989, Samoilys 1989), but the accuracy and biases of this method needs to be considered. A measure of the accuracy of the method is necessary when knowledge of the absolute abundance is required. Accuracy is defined as the closeness of a measured or computed 
value to its true value' (Sokal \& Rohlf 1981). Bias is repeated under-or over-estimation of the true value - it is inaccuracy in a constant direction.

The accuracy of visual estimates of abundance and species richness has been examined by comparing such estimates either to results obtained by other, independent techniques of visual censuses ( Sale \& Douglas 1981, Sale \& Sharp 1983, Kimmel 1985) or to the results of subsequent destructive sampling of the same area (Sale 1980b, Brock 1982, Thresher 1983, Fowler 1987). But visual censuses and destructive sampling techniques have bias. The assumption that you do not count what you do not see in visual censuses has led to a general conclusion that visual censuses under-estimate the true value (e.g. Russell et al. 1978). Thus when comparing visual methods of estimation of the size of fish populations, the largest estimate of abundance is often considered the most accurate (Sale \& Douglas 1981, Sale \& Sharp 1983). It is, in fact, difficult to determine which method is more accurate when estimates from various techniques differ (Andrew \& Mapstone 1987).

Some studies have purported to examine the accuracy of visual estimates of the size structure of live coral reef fish (Ogden \& Ehrlich 1977, GBRMPA 1978, Craik 1981, Ayling \& Ayling 1984, Bell et al. 1985, Bellwood \& Alcala 1988). The accuracy of visual estimate of length of fishes was assessed by either comparing estimates with the sizes of collected individuals from the area (Ogden \& Ehrlich 1977), or with the results obtained by 'trained' observers, who were considered to be more accurate (GBRMPA 1978, 1979, Craik 1981, Bell et al. 1985). In GBRMPA (1979), accuracy was determined by comparison of estimates of lengths with lengths of model fish. In only one study (Bellwood \& Alcala 1988), visual estimates of the length of the fish were compared to their measured lengths ( $n=18$ fish). The accuracy of visual estimates of both length and number of fish has not been examined. Also, the accuracy of biomass calculated from visual estimates of the size-structure of reef fishes has not been examined.

Many factors contribute to the accuracy of a visual census. The degree of effort made by an individual worker to estimate correctly the number of species or the number and/or size of fishes of a particular species is important (Sale 1980b). Part of this effort is related directly to the time spent surveying the reefs. Many authors have not specified the time taken to census small patch reefs (Russell et al. 1977. Williams 1980) and it was thus implicit that the duration of the census was sufficient to count the majority of individuals and/ or species of fish. Sale \& Douglas $(1981,1984)$ and Sale \& Steele (1986) spent 10 to 40 min surveying single patch reefs ranging in size from 2.71 to $28.35 \mathrm{~m}^{2}$ Molles (1978) estimated species richness on patch reefs by surveying until no additional species were recorded for $5 \mathrm{~min}$. In all of these studies, the time spent surveying reefs relied on a decision by the observer that (almost) every species or individual had been seen. No study which utilized visual censuses of fishes on patch reefs examined whether different durations of census affected the accuracy of estimates of density and size structure.

This study assessed the accuracy and bias of visual estimates of the number, size structure and biomass of a population of a moderately sedentary fish (Russ \& St. John unpubl.). It examines differences among 3 observers surveying reefs for 3 census durations to estimate the number and size-structure of fish on reefs. Juveniles of the species used in this study, Salarias fasciatus, were considered a priori to be easy to survey visually and to capture. S. fasciatus is a small (15 to 145 mm Total Length, TL), herbivorous blenny which lives on branching and honeycombed dead coral patch reefs at One Tree Reef, Great Barrier Reef. The experimental patch reefs used in the study were typically covered in crustose coralline algae, turfing and macro-algae and provided an apparently uniform habitat for $S$. fasciatus.

\section{MATERIALS AND METHODS}

Two experimental sites were located in adjacent shallow sand sheets on the South Reef Flat of One Tree Reef $\left(23^{\circ} 30^{\prime} \mathrm{S}, 152^{\circ} 06^{\prime} \mathrm{E}\right)$, Great Barrier Reef. In November 1987, 32 artificial reefs were constructed at each site. Reefs were located $20 \mathrm{~m}$ apart and at least $20 \mathrm{~m}$ from other hard substrata. Each reef (ca $1 \times 0.8 \times$ $0.7 \mathrm{~m}$ in size) consisted of 1 or 2 pieces of dead coral and was wired onto a base of 2 cement blocks $(40 \times 20$ $\times 20 \mathrm{~cm}$ ). The blocks held the coral above the sand and prevented the reefs from subsiding. The top of each reef was approximately at the level of Mean Low Water. These reefs were similar to natural patch reefs found in other areas of the South Reef Flat (in terms of substratum type, size and structural complexity) where Salaria fasciatus were abundant. By January 1988 S. fasciatus had recruited to all reefs. Subsequent captures from reefs determined that densities of recruits ranged from 1 to 25 fish reef ${ }^{-1}$.

Study design and analyses. The study was done in mid January 1988 and 1989 and the recruitment patterns of juvenile Salarius fasciatus were compared over the 2 years by Contingency Table (GLIM 1985). The numbers of juvenile fish on the reefs at each site in both years were compared by a 2-factor Analysis of Variance (ANOVA). Each of the factors had 2 levels. 'Years' was a random factor and 'Sites' was fixed because both sites were chosen for the experiment (Underwood 1981). 
All the surveying and collecting was done at low tide by snorkelling between 10:00 and 16:00 h. In 1988, 5 randomly chosen reefs at each site were surveyed by 3 observers for 3 independent periods (5, 10 and 15 $\min$ ). Both the order of the observers and the duration of census were randomized for every reef and the time between consecutive censuses on each reef ranged from 10 min to $2 \mathrm{~h}$. Each observer approached the reef from a random direction and waited several minutes at the reef before beginning the census. Each reef was surveyed 9 times on the same day. In every census the number and total length (to the nearest $5 \mathrm{~mm}$ ) of juvenile Salarius fasciatus were estimated. The midpoints of the juvenile size-classes were $15,20,25,30$, 35,40 and $45 \mathrm{~mm}$. Immediately after the censuses, all fish were collected from the surveyed reefs using handnets and Quinaldine. The numbers and total lengths of these fish were determined. The effect of different observers and durations of census were examined by a Mixed Model Analysis of Variance with 4 factors in the design. The 4 factors were Sites (with 2 levels: Site 1, Site 2), Reefs nested within Sites (5 reefs at each site), Times (with 3 levels: 5, 10, and $15 \mathrm{~min}$ periods) and Observers (with 3 levels: A, B and C). Reefs were considered a factor because each reef was visited by each Observer for 3 durations of census (Times). Sites and Times were considered fixed factors whereas Reefs and Observers were random (Underwood 1981). The Fdistribution and associated degrees of freedom were approximated for some of the mean squares. Satterthwaites method of calculation (cited in Winer 1971) was used to determine quasi F-ratios and associated degrees of freedom.

The length frequency data were analyzed by Loglinear Analysis which examined variation in the counts of fish due to size-classes, census methods (visual counts or collected number), time of census, Observers and Sites and the interactions between all of the factors.

In 1989 one observer (J.S.J.) estimated the number and the length of fish visually on 5 random reefs at each of the 2 sites surveyed in 1988 . Each reef was surveyed for $10 \mathrm{~min}$. The methods were identical to those used in 1988 (visual censuses were followed by destructive sampling) except that the reefs were only surveyed once. These results were compared to results on the same observer for the $10 \mathrm{~min}$ census period in 1988 The accuracy of estimates of numbers of fish for each year were analyzed by a 2-factor ANOVA (design exactly as that used for analysis of the number of juvenile fish on reefs at each site). In addition to the methods of 1988, each captured fish was weighed for direct comparison with the estimated biomass calculated from visual census. The biomass for each size class was calculated using the length-weight relation- ship, In weight $=3.178 \times \ln$ length $-11.813, \mathrm{r}^{2}=0.976$ (length $=$ midpoint of the size classes), which was calculated from 1989 Salarius fasciatus (size range 15 to $49 \mathrm{~mm}$ ) collected on the South Reef Flat in January 1989. Model 1 Linear Regression analysis was used to determine the length-weight relationship.

There are 3 steps involved in deriving biomass from visual estimates and all 3 have associated error: (1) estimating the number and length of fish visually; (2) assigning each fish into a size class (the magnitude of this error is dependent on the size of these classes); (3) calculating the weight of the fish from the appropriate length-weight relationship.

To estimate the error associated with these steps, 3 separate estimates of total biomass of Salarius fasciatus on each reef were derived using the length-weight relationship where lengths were determined from: (1) visual estimates (within $5 \mathrm{~mm}$ ); (2) real size classes (measured lengths within $5 \mathrm{~mm}$ ); (3) real lengths (TL measured to $1 \mathrm{~mm}$ ). The error related specifically to visual estimates of length was the difference between the accuracy of the biomass calculated from visual estimates (1) and accuracy of the biomass calculated from the real size-class (2). The error associated with classing the fish into $5 \mathrm{~mm}$ size-classes was the difference between the accuracy of biomass calculated from the real size-classes (2) and those calculated from the real measurements (3). The error attributed to converting length of fish to biomass using the length-weight relationship was represented by the difference between the accuracy of the weighed biomass and accuracy of the biomass calculated from measured lengths (3). This last component of error may also represent imprecision in length and/or weight measurements of fish as well as the natural biological variability within the species

A Split Plot Factorial design was used to compare the biomass derived from (1) visual estimates, (2) true sizeclasses and (3) true lengths between sites. Reefs, nested in Sites, were considered a factor because the same reef was used by each observer for every time period and so the design was unreplicated.

In this study, accuracy was calculated as estimated value/true value. This calculation of accuracy was used because there were differences in the number and biomass of fish on the reefs at each site. Thus, values less than 1 are under-estimates, values equal to 1 are accurate and values greater than 1 are over-estimates. In general, estimates are not biased if the raw mean deviation of the estimated value from the true value equals zero. This null hypothesis was tested for estimates of number and biomass of fish using t-tests [special case, single observation $(x=0)$ compared with the mean of a sample; Winer 1971]. This test gives the probability range of obtaining zero as a variate in the 
Table 1. Salarius fasciatus. Recruitment to each site (reefs pooled) in both years (from destructive collections) and mean estimated number of fish in 1988 (in $5 \mathrm{~mm}$ size-classes). Visually estimated counts are averaged for each observer over each time period

\begin{tabular}{|c|c|c|c|c|c|c|c|c|c|}
\hline & & \multicolumn{7}{|c|}{ Size categories (mm) } & \multirow[t]{2}{*}{ Total } \\
\hline & & 15 & 20 & 25 & 30 & 35 & 40 & 45 & \\
\hline \multirow{4}{*}{1988} & Site 1 & 7 & 15 & 16 & 8 & 7 & 3 & 1 & 57 \\
\hline & (estimated) & 4.2 & 17 & 12.5 & 8.1 & 7.7 & 2.6 & 1.1 & 53.2 \\
\hline & Site 2 & 0 & 5 & 5 & 2 & 2 & 4 & 0 & 18 \\
\hline & (estimated) & 0 & 3.2 & 3.2 & 3.1 & 2.2 & 3.5 & 0.55 & 12.5 \\
\hline \multirow{2}{*}{1989} & Site 1 & 13 & 7 & 4 & 1 & 0 & 0 & 0 & 25 \\
\hline & Site 2 & 8 & 12 & 22 & 0 & 0 & 0 & 0 & 42 \\
\hline
\end{tabular}

population of raw deviations for each group. When this probability is small ( $p<0.05$ ), the estimate is biased.

Collection of fish. When destructively sampling the reefs, the collectors knew the estimated number of fish on each reef. The collection was done systematically from one side of the reef to the other moving in the same direction as the current. Individual fish, when sighted, were caught by gently squirting a small quantity of diluted Quinaldine into the current until the fish was anaesthetized. The anaesthetized fish was flushed out of the reef and into a net by a current made with the hand. Squirting Quinaldine near the reef chases out other juveniles from their refuges and these fish were watched and netted when they became partially anaesthetized. Because blennies are benthic dwelling fishes with smail swim bladders, anaesthetized juveniles were slightly buoyant. The current was never strong enough to wash the anaesthetized juveniles away from the reef. After carefully searching the reef for fish once and when every juvenile was considered captured, the reef was surveyed visually for an additional $5 \mathrm{~min}$.

In this study the juvenile Salarius fasciatus caught with Quinaldine were considered to be the most complete population of fish on the reefs. This assumption was tested by one observer who re-surveyed and recollected any remaining fish from the 10 reefs between 1 and $2 \mathrm{~h}$ after the first clearance. In these subsequent censuses only one fish was seen and collected. This indicated that the fish collected from the 10 reefs during the first clearance represented $98.5 \%$ of the closest estimate to the actual fish present on these reefs. This estimate could have been improved by breaking up each patch reef and searching through the interstices. The data from the initial clearance will hereafter be called 'true number', 'true size structure' (from measured lengths) and 'true biomass' (from measured weights) but we acknowledge that these destructive samples cannot represent the absolute population.

\section{RESULTS}

Patterns of recruitment of juvenile Salarius fasciatus to the reefs are shown by the size-structure of the fish on each reef at each Site (Table 1). The size-structure of the fish populations varied between the 2 years (Kolmogorov Smirnov 2-sample t-test, $p<0.01$; Sokal \& Rohlf 1981). In 1988, $35 \%$ of fish collected in midJanuary were $30 \mathrm{~mm}$ or larger, whereas in 1989 most of the fish $(98.5 \%)$ were less than $30 \mathrm{~mm}$. Site 2 had a smaller size range of fish in both years. In 1988 the size distribution of the fish varied significantly between the sites. The number of juvenile $S$. fasciatus on artificial reefs varied between the 2 sites in both years (ANOVA Year $\times$ Site interaction, $F=11.22,1 / 16 \mathrm{df}, \mathrm{p}<0.01)$. In 1988 , fish were significantly more abundant on reefs at Site $1(\bar{X}=11.6, \mathrm{SE}=1.86)$ than at Site $2(\overline{\mathrm{X}}=3.61, \mathrm{SE}$ $=0.81$ ) but this trend reversed in 1989, when there were more fish at Site $2(\bar{X}=8.39, \mathrm{SE}=2.54)$ than at Site $1(\bar{X}=5.0, S E=0.99)$. In the lagoon of One Tree Reef, recruitment of $S$. fasciatus to artificial patch reefs varied both spatially and temporally

The accuracy of the visual estimates of numbers by Observer $A$ in both years were compared for the $10 \mathrm{~min}$ census period to determine whether accuracy differed between years. There was no significant difference in the accuracy of counts by Observer A in 1988 or 1989 at both sites (ANOVA ns for Year, Site and Year $\times$ Site). The mean accuracy in 1988 was 0.971 (SE $=0.06$ ) and $0.876(\mathrm{SE}=0.04)$ in 1989 .

\section{Estimates of fish numbers}

The accuracy of estimates of the numbers of fish on each reef by the 3 observers varied between sites (ANOVA, interaction between Observer $\times$ Site, $p<0.05$; Table 2). The Observer $\times$ Site interaction was 
Table 2. Analysis of Variance of accuracy of estimates of numbers of fish on experimental patch reefs. Sites (with 2 levels) and Times (with 3 levels, 5, 10 and $15 \mathrm{~min}$ ) are fixed factors and Observers (with 3 levels) and Reefs, nested in Sites, are random. Source: source of variation; df: degrees of freedom; MS: mean square; F: F-value; $n / d$ : degrees of freedom of the F-value for numerator $(n)$ and denominator (d); $p$ : probability where $p<0.05, \cdots p<0.001$ Underlined Fvalues are quasi F-ratios calculated using Satterthwaite's method (cited in Winer 1981)

\begin{tabular}{|c|c|c|c|c|c|}
\hline Source & $\mathrm{df}$ & MS & $F$ & $\mathrm{n} / \mathrm{d}$ & $\mathrm{p}$ \\
\hline Site & 1 & 0.058 & 0.639 & $4 / 3$ & ns \\
\hline $\operatorname{Reef}(\mathrm{S})$ & 8 & 0.157 & 2.606 & $8 / 16$ & - \\
\hline Observer & 2 & 0.021 & 0.343 & $2 / 16$ & ns \\
\hline $\mathrm{S} \times \mathrm{O}$ & 2 & 0.285 & 4.723 & $2 / 16$ & $\cdot$ \\
\hline$O \times R(S)$ & 16 & 0.060 & - & & \\
\hline Time & 2 & 1.014 & 11.386 & $2 / 12$ & $\cdots$ \\
\hline $\mathrm{S} \times \mathrm{T}$ & 2 & 0.003 & 1.156 & $34 / 16$ & ns \\
\hline$T \times R(S)$ & 16 & 0.037 & $\overline{0.745}$ & $16 / 32$ & ns \\
\hline $\mathrm{O} \times \mathrm{T}$ & 4 & 0.056 & 1.151 & $4 / 32$ & ns \\
\hline $\mathrm{S} \times \mathrm{O} \times \mathrm{T}$ & 4 & 0.009 & 0.183 & $4 / 32$ & ns \\
\hline $\mathrm{O} \times \mathrm{T} \times \mathrm{R}(\mathrm{S})$ & 32 & 0.049 & - & & \\
\hline
\end{tabular}

caused by Observer $C$, who had the highest accuracy in Site 1 and the lowest in Site 2. Observer $C$ had no previous experience of surveying Salarius fasciatus visually. Also, the accuracy of the estimates of numbers of fish varied among reefs within sites (ANOVA, $p<0.05$; Table 2).

The accuracy of the estimates of numbers of fish differed significantly among the durations of census (ANOVA, $p<0.001$; Table 2). The mean accuracy of the numbers of fish observed on the reefs in 5 min was 0.682 and this was significantly lower than the $10 \mathrm{~min}$ census period (mean $=0.916$ ) and the 15 min census period $($ mean $=1.044$, SNK test $p<0.01,5 \underline{10} 15 ;$ Fig. 1). In the 15 min census, the estimated numbers of fish on each reef were over-estimates (accuracy $>1$ ), whereas the numbers of fish were under-estimated for both the 5 and 10 min census.

The observers were not biased in their counts of

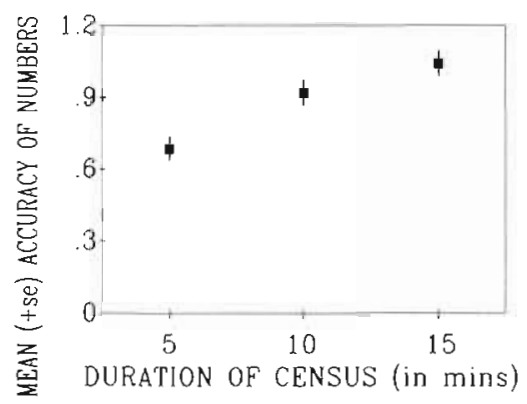

Fig. 1. Salarius fasciatus. Mean accuracy of estimates of number on each reef for censuses of 3 durations $(5,10$ and 15 min). The 3 observers were pooled. Standard error is based on the pooled variance
Table 3 . Biases of estimating numbers of fish on reefs for the 3 observers (A, B and C) during 3 census periods. Raw deviation = estimated number - true number for each of 5 reefs at each site. A zero variate means that the method of estimating the total number of fish on each reef is unbiased. The biases were expressed as a probability range of obtaining zero as a variate in the population of raw deviations. If the probability of obtaining zero in the population was $5 \%$ or less, then the observer would be biased. In this case, the sign of the mean raw deviation would indicate the direction of bias

\begin{tabular}{|rrrrr|}
\hline & & Observer A & Observer B & Observer C \\
\hline & 5 & $20-40 \%$ & $10-20 \%$ & $20-40 \%$ \\
Site 1 & 10 & $50-90 \%$ & $50-90 \%$ & $50-90 \%$ \\
& 15 & $50-90 \%$ & $>90 \%$ & $50-90 \%$ \\
& 5 & $40-50 \%$ & $50-90 \%$ & $20-40 \%$ \\
Site 2 & 10 & $50-90 \%$ & $50-90 \%$ & $50-90 \%$ \\
& 15 & $50-90 \%$ & $>90 \%$ & $>90 \%$ \\
\hline
\end{tabular}

Salarius fasciatus at either site (Table $3 ; p>0.05$ ) or for any census duration. At Site 1, where more fish were present, the probability of the observers being unbiased (probability that the raw deviation $=0$ would fall in the sample population) increased as the duration of census increased. This was most evident for Observer B. At $5 \mathrm{~min}$, the probability of a zero variate (a raw deviation which equalled zero) falling into the sample population was 10 to $20 \%$ (Table 3). At $15 \mathrm{~min}$, this probability increased to $>90 \%$ (Table 3 ).

\section{Estimates of size structure}

The final model from the Contingency Table involved the terms Size, Method, Time, Site, Size $\times$ Method, Method $\times$ Time, Method $\times$ Observer, Size $\times$ Site and Size $\times$ Method $\times$ Observer (deviance $=83.7$. $\mathrm{df}=129$ ). Overall, the counts of fish varied among the size-classes and the 3 times of census, and between the methods (estimated visually or collected) as well as the 2 sites.

The estimates of number of fish by the observers differed from the collected number (Method $x$ Observer) and these 2 methods differed between the size classes (Method $\times$ Size). The estimates of the length of fish by observers varied among size classes of fish and these estimates differed from the true counts (Size $\times$ Method $\times$ Observer). The pattern of bias in the estimates of length varied for each observer (Fig. 2). Observer A tended to under-estimate the length of fish in the upper size range because the total counts in these size classes were much lower. Accuracy for the 40 and the $45 \mathrm{~mm}$ size classes were much lower than the mean accuracy of each size class (mean for Observer $A$ $=0.773$ ). Mean accuracy for these 40 and $45 \mathrm{~mm}$ size 


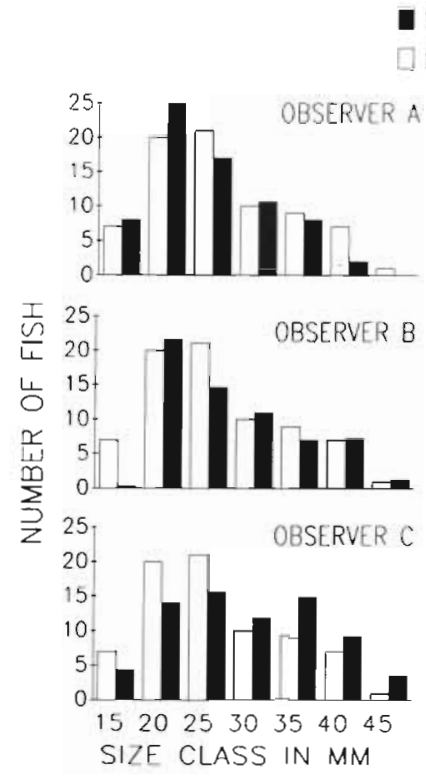

Fig. 2. Salarius fasciatus. True and the mean estimated size structure of the population at both sites (pooled for times) for each observer. Standard error is based on the pooled variance

classes was 0.25 and 0 respectively. Observer $B$ had the lowest total counts of all the observers and either missed or over-estimated most of the smallest fish. The accuracy of Observer B for the $15 \mathrm{~mm}$ size class was 0.042 . Overall, Observer B had the highest mean accuracy of each size-class (mean $=0.865$ ). Observer $\mathrm{C}$ had a clear and consistent bias in estimation of length because generally the lengths of fish were over-estimated (Figs, 2 and 3). The 3 smaller size classes were all under-represented and the rest of the size classes were all over-represented. Although Observer $\mathrm{C}$ was the least accurate judge of lengths of fish (mean accuracy $=1.25$ ), this observer had the best estimate of the total number of fish on reefs.

The length distribution of the fish varied between the 2 sites (Size $\times$ Site; Table 1 ). The estimated and true totals for each site (pooled over Observers and Times) summarize the total length frequency data (Table 1). The mean accuracy for each size class for each site (pooled over Observers and Times) was 0.859 and this means that on average, for any size class $86 \%$ of fish and that size class were recorded correctly.

The estimates of counts varied among the durations of census (Method $\times$ Time). The 10 min census was the best estimate of the true total $(10 \mathrm{~min}$ total $=71.3$; true total $=$ 76.3) for both sites and this was consistent among the size classes of the fish. For both sites the total of the mean estimate for the $5 \mathrm{~min}$ census under-estimated the true total (total estimate $=53.0$ ), whereas the 15 min census over-estimated the true total (total estimate $=83.6$ ). This result corroborates the results of the analyses of the estimates of numbers for the duration of census.

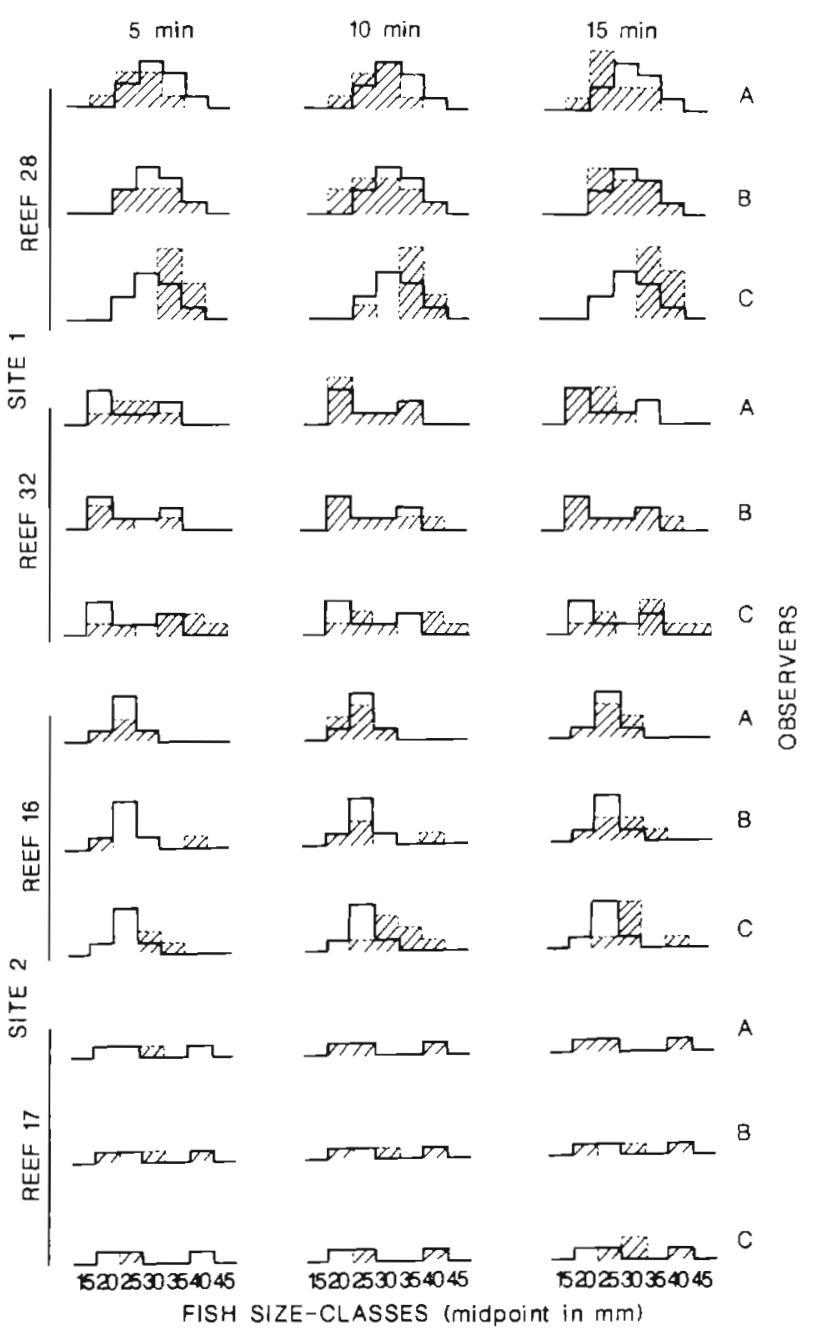

Fig. 3. The true (open) and estimated (hatched) size structure of the population of Salarius fasciatus for 2 reefs at each Site by each observer for the three durations of census

\section{Estimates of biomass}

The accuracy of biomass calculated from estimations of length differed significantly among the 3 methods used to estimate length (ANOVA, Method $=p<0.001$; Table 4). The accuracy of biomass estimates derived using visual censuses to estimate length was significantly lower (mean accuracy $=0.723$ ) than the accuracy of biomass estimates derived using true lengths, as either $5 \mathrm{~mm}$ categories (mean accuracy $=0.961$ ) or measured to $1 \mathrm{~mm}$ (mean accuracy $=1.026$, SNK, $p<0.01$, Visual Estimates $5 \mathrm{~mm} 1 \mathrm{~mm}$; Fig 4).

The biomass derived from the lengths of fish estimated by 3 different methods was not biased at any site (Table 5). The raw deviation of the biomass (estimated biomass - true biomass) derived from lengths esti- 
mated by visual census was the largest deviation obtained $(\overline{\mathrm{X}}=-0.328, \mathrm{SE}=0.131)$. In this data set, all the signed deviations were negative. So, estimates of biomass derived from visual census were under-

Table 4. Split Plot Design of the accuracy of the 3 estimates of biomass derived from different estimates of length (factor $=$ Method) at 2 sites. The 3 methods were lengths estimated visually, true lengths placed in $5 \mathrm{~mm}$ categories and true lengths measured to $1 \mathrm{~mm}$. Site and Method were fixed factors. Reefs, nested in Site, was a random factor. Variances are homogeneous (Cochrans test, ns at $p<0.05$, Cochrans value $=0.385$ ). Source: source of variation; $\mathrm{df}$ : degrees of freedom; MS: mean square; F: F-value; $n / d$ : degrees of freedom of the F-value for numerator (n) and denominator (d); $\mathrm{p}$ : probability where $\mathrm{p}<0.05, \cdots p<0.001$

\begin{tabular}{|lrrrrl|}
\hline Source & df & MS & F & n/d & p \\
\hline Site & 1 & 0.1976 & 4.2658 & $1 / 8$ & ns \\
Reef(S) & 8 & 0.0463 & 3.1195 & $8 / 16$ & $\cdot$ \\
Method & 2 & 0.2497 & 16.8162 & $2 / 16$ & $\cdots$ \\
S $\times$ M & 2 & 0.0151 & 1.0232 & $2 / 16$ & ns \\
M $\times$ R(S) & 16 & 0.0148 & & & \\
\hline
\end{tabular}

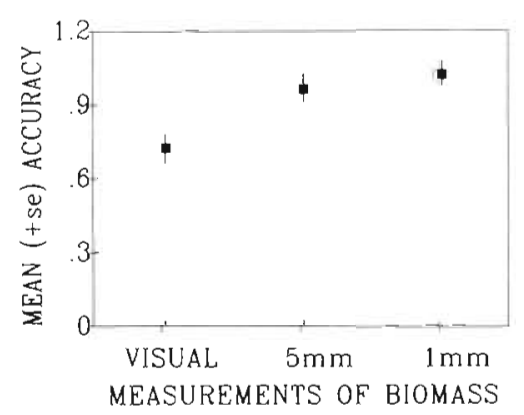

Fig. 4. Salarius fasciatus. Mean accuracy of estimates of biomass derived from visually estimated lengths (in $5 \mathrm{~mm}$ size classes), true size-classes (measured fish in $5 \mathrm{~mm}$ size classes) and true lengths (measured to $1 \mathrm{~mm}$ ) of fish. Standard error is based on the pooled variance

Table 5. Biases of methods of estimating biomass expressed as a probability range of obtaining zero as a variate in the population of raw deviations. Raw deviation = estimated biomass - true biomass for each of 5 reefs at each site. A zero variate means that the method of estimating the total biomass of fish on each reef is unbiased. The biases were expressed as a probability range of obtaining zero as a variate in the population of raw deviations. If the probability of obtaining zero in the population was $5 \%$ or less, then the observer would be biased. In this case, the sign of the mean raw deviation would indicate the direction of bias

\begin{tabular}{|c|c|c|c|}
\hline & \multicolumn{3}{|c|}{ Biomass derived from lengths determined from - } \\
\hline & $\begin{array}{l}\text { Visual } \\
\text { census }\end{array}$ & $\begin{array}{l}5 \mathrm{~mm} \text { size- } \\
\text { classes }\end{array}$ & $\begin{array}{l}1 \mathrm{~mm} \text { measure- } \\
\text { ments }\end{array}$ \\
\hline Site 1 & $40-50 \%$ & $50-90 \%$ & $50-90 \%$ \\
\hline Site 2 & $20-40 \%$ & $20-40 \%$ & $40-50 \%$ \\
\hline
\end{tabular}

estimating the total biomass of fish on each reef. The estimates of biomass derived from the true lengths had raw deviations of both signs which reduced the mean of the raw deviations.

\section{DISCUSSION}

The accuracy of visual census in estimating the number, size-structure and biomass of fish populations was high in this study. The accuracy of estimates of numbers was $91.6 \%$ for the optimal census period (10 min). The mean accuracy of estimates of length was $86.0 \%$ pooled over observers and the accuracy of the biomass derived from visual estimates of length was $72.3 \%$. As the accuracy of estimates decreases, biological differences measured either relatively or absolutely become more difficult to detect. If an accuracy of $72 \%$ is the best obtainable for estimates of biomass under conditions which are excellent for visual censuses, then the accuracy of biomass estimates for visual censuses of larger mobile species can only be expected to be worse and their usefulness must be diminished.

The biomass estimates derived from visual census consistently under-estimated the true biomass of fish on reefs. Yet, visual censuses were an unbiased method of estimating total biomass using the length-weight relationship because the probability of the visual estimates being accurate was greater than $p=0.05$. The biomass estimates derived from visual censuses were not as accurate as estimates of biomass derived from the 2 true lengths, the $5 \mathrm{~mm}$ categories and the lengths measured to $1 \mathrm{~mm}$. The 2 mean estimates of biomass derived from true length $15 \mathrm{~mm}$ and $1 \mathrm{~mm}$ categories) were within $4 \%$ of the true biomass assessed by destructive collections, but biomass estimates derived from visual census were only within $28 \%$ of this true biomass. This large difference suggests that most of the error in estimating biomass is associated with estimating the length of fish visually. The error associated with converting the length of fish to biomass using the length-weight relationship and the error associated with the effect of categorising fish were minimal.

The lengths of fish were estimated most accurately by the 2 observers with prior experience of surveying Salarius fasciatus (mean accuracy for each size class of total counts $=0.773$ and 0.865 ). Yet, both of these observers showed unique patterns of bias in their estimation of lengths of fish in specific size-classes. Unless an observer has consistent bias, individual variations in accuracy among size classes are difficult to detect. The results of this study suggest that when complex variations in estimating length of fish occur, pooling the results of accurate observers may produce more accu- 
rate results. The other observer repeatedly over-estimated the lengths of fish and the mean accuracy of the total counts for each size class reflects this bias (mean = 1.25). But the bias of this observer was consistent and therefore measurable. So the estimates of length by this observer could be altered to produce a more accurate result. Over-estimation of the lengths of small fish is not consistent with other studies where lengths of small fish were generally under-estimated (e.g. GBRMPA 1978).

The duration of census affected the accuracy of estimates of numbers of fish; however, longer periods of census did not improve estimates in proportion to the effort expended. The most accurate visual estimates of numbers of Salarius fasciatus were achieved in the 15 min census but this accuracy did not differ significantly from that obtained in the 10 min census. Thus, the 10 min census period was considered optimal because the results of these censuses were accurate and most timeefficient. The log-linear analysis showed that the total number of fish in the 10 min census period was closest to the true total. There is no single census time best for any study. Bohnsack \& Bannerot (1986) showed that a 5 min census was optimal compared to a 10 min census in their study in Florida, USA.

The accuracy of estimates of numbers of fish in this study is high in comparison to other studies where visual censuses were followed by destructive sampling. The accuracy of estimates of numbers of coral reef fishes in 3 studies (Sale 1980b, Brock 1982, Fowler 1987) was calculated using the same mathematical methods used in this paper (estimated number/true number). Brock (1982) surveyed one large patch reef and then collected a total of 43 species of fish from that reef using the poison Rotenone. The accuracy of estimating numbers of 35 different species lomitting species absent in the Rotenone sample because we are not concerned with the accuracy of sampling with rotenone) ranged from $0(\mathrm{n}=3)$ to $3.0(\mathrm{n}=3)$ with a mean of 1.047. For a cryptic species, Asteropteryx semipuctatus, 77 fish were counted from a total of 988 fish collected. Sale (1980b) surveyed 3 patch reefs and then collected the fish using Quinaldine, nets and spears. The accuracy of the visual census was 1.281, 1.346 and 1.170 for the 3 reefs. Fowler (1987) used transects to count numbers of 3 species of chaetodontids. Mean estimated densities (per $150 \mathrm{~m}^{2}$ ) were compared to mean collected densities of each species of fish. The mean accuracy for 4 large patch reefs was $1.077,0.567$ and 0.675 for Chaetodon rainfordi, C. plebius and Chelmon rostratus respectively. Although the accuracy of estimates of numbers of Salarius fasciatus (1.045, SE $=0.001$ for $15 \mathrm{~min}$ ) was similar to Brock's, this study was more precise because the standard error around Brock's mean was an order of magnitude larger ( $\mathrm{SE}=$
0.022). The high accuracy in our study occurred for at least 2 possible reasons. Firstly, juveniles of a single species of a sedentary fish such as $S$. fasciatus on small artificial patch reefs could be easier to count accurately than an assemblage of species on patch reefs (e.g. Sale 1980 b, Brock 1982) or a species of fish on large reefs (e.g. Fowler 1987). Secondly, the destructive collections of fish using Quinaldine in this study may have been more complete than the collections in the other studies.

The accuracy of estimates of number of Salarius fasciatus differed significantly between observers at different sites and this was due to one observer who was not experienced in surveying $S$. fasciatus. In other studies using stationary visual censuses, observers did not affect the estimates of abundance of fish (Bohnsack \& Bannerot 1986, Thresher \& Gunn 1986). Yet, variations in the amount of area actually surveyed (caused by errors in estimations of distance) led to differences in estimates of abundances by observers when the methodology of visual censuses included an estimate of the distance of the fish from the observer (Bohnsack \& Bannerot 1986).

All methods of estimating and collecting fish have bias. The 3 visual census studies cited above all acknowledged biases in their methods used to collect fish. During counting and subsequent collecting of all fish, individuals were often missed from either the census or the collection (Sale 1980b). Cryptic fish were omitted from the visual census and active midwater foragers were not collected in subsequent destructive sampling using Rotenone even though they were present in the census (Sale 1980b). Sale (1980b) concluded that visual censuses of assemblages, which include cryptic species, will be more likely to under-estimate counts of fish than in those assemblages with more midwater foragers. Other biases inherent in visual censuses are discussed rarely. The effect of some of these may have been reduced in this study. Boundary effects and problems of inclusion and exclusion of borderline fish from the census (discussed in Andrew \& Mapstone 1987) were eliminated because of the isolated nature of the reefs and because juvenile Salarius fasciatus did not appear to move between reefs during the study. Thus, each artificial reef probably included the whole home ranges of these resident fish. The effects of the presence of the diver on fish were minimized because these small fish displayed little sign of avoidance of divers. Also, the effect of water visibility was reduced because the fish were small and the observers were close to the reef during the census.

Visual censuses do not always under-estimate abundances of fish. In the studies reviewed (Sale 1980b, Brock 1982, Fowler 1987) visual censuses over-estimated abundance of fish by an average of $41.5 \%$ Over-estimation of abundance was greatest when total 
assemblages of fish were surveyed. Over-estimation of total fish (species unknown) occurred for all 3 patch reefs examined by Sale (1980b) and for 18 out of a total of 43 species ( $42 \%$ over-estimation) surveyed by Brock (1982). In censuses of single-species, over-estimation occurred less frequently. In this study, over-estimation of fish on reefs occurred on 2 reefs out of 10 (Times and Observers pooled). Fowler (1987) over-estimated the mean abundances of one species of fish out of 3 . This high level of over-estimation of numbers of fish in visual censuses could reflect the biases and inadequacies in the subsequent methods of destructive collection (e.g. fish avoiding the net, loss to collectors by lodging in inaccessible crevices, eaten by scavengers). Fish loss is more likely to occur when using Rotenone because the fish die and sink, and many are eaten by invertebrate predators. Salarius fasciatus recover quickly from the effects of Quinaldine and often return to their refuge (Russ \& St. John unpubl.). The effectiveness of destructive techniques, however, will vary among species, sites and times depending on habitat and current conditions.

Even though the accuracy attained in this study is species and site specific, and not every study utilizing visual censuses will expect to achieve such accuracy, the results demonstrate some important considerations needed to improve the accuracy of visual censuses. More importantly, this study shows that it is difficult to obtain highly accurate estimates of biomass for populations of reef fish using visual censuses even under very favourable circumstances. Thus, accurate estimates of biomass derived from visual censuses are likely to be more difficult to obtain for large, highly mobile species of reef fishes.

Acknowledgements. This manuscript was greatly improved by discussions with Bruce D. Mapstone. Two statisticians, Brian McArdle, Univ of Auckland and Glen De'ath, J.C.U., contributed to the analyses of this data. We are grateful for their help, especially Glen who did the Log-linear Analysis. We thank Jean G. Deklerk for assistance in the field. We also thank Mark and Maryanne Sewell and Stewart Jackson and Kira Schlusser for their help on One Tree Island. This work was funded by a Marine Sciences and Technology Grant Scheme (to G.R.R.). This is a contribution from the One Tree Island Field Station.

\section{LITERATURE CITED}

Alm, G. (1959). Relation between maturity size and age in fishes. Rep. Inst. Freshwat. Res. Dottningholm 40: 5-146

Andrew, N. L., Mapstone, B. D. (1987). Sampling and the description of spatial pattern in marine biology. Oceanogr. mar. Biol. A. Rev. 25: 39-90

Ayling, A. M., Ayling, A. L. (1984). Determination of most accurate survey size and method for visual counting of Coral Trout (Plectropomus spp.) Report to Great Barrier Reef Marine Park Authority, Townsville
Bell, J. D., Craik, G. J. S., Pollard, D. A., Russel, B. C. (1985). Estimating length frequency distributions of large reef fish underwater. Coral Reefs 4: 41-44

Bellwood, D. R., Alcala, A. C. (1988). The effect of minimum length specification on visual estimates of density and biomass of coral reef fishes. Coral Reefs 7: 23-27

Bohnsack, J. A., Bannerot, S. P. (1986). A stationary visual census technique for quantitatively assessing community structure of coral reef fishes. NOAA Tech.Rep. NMFS 41 $1-15$

Brock, R. E. (1982). A critique of the visual census method for assessing coral reef fish populations. Bull. mar Sci. 32 269-276

Craik, G. J. S. (1981). Underwater survey of coral trout Plectropomus leopardus (Serranidae) populations in the Capricornia section of the Great Barrier Reef. Proc. 4th Int. Coral Reef Symp. 1: 53-58

Fowler, A. J. (1987). The development of sampling strategies for population studies of coral reef fishes. A case study. Coral Reefs 6: 49-58

GBRMPA (1978). Great Barrier Reef Marine Park Authority workshop on reef fish assessment and monitoring. Workshop series no. 2, GBRMPA, Townsville

GBRMPA (1979). Great Barrier Reef Marine Park Authority workshop on coral trout assessment techniques. Workshop series no. 3, GBRMPA, Townsville

GLIM (1985). The Generalized Linear Interactive Modelling System, release 3.77. Numerical Algorithm Group, Oxford

Harmelian-Vivien, M. L., Bouchon-Navaro, Y (1981). Trophic relationships among chaetodontid fishes in the Gulf of Aquaba (Red Sea). Proc. 4th Int. Coral Reef Symp. 2: $537-544$

Jones, G. P. (1987). Competitive interactions among adults and juveniles in a coral reef fish. Ecology 68 (5): 1534-1547

Kimmel, J. J. (1985). A new species-time method for visual assessment of fishes and its comparison with established methods. Environ. Biol. Fish. 12: 23-32

Kulbicki, M. (1989). Correlation between catch data from bottom longlines and fish censuses in the S.W. lagoon of New Caledonia. Proc. 6th Int. Coral Reef Symp. 2: 305-312

McCormick, M. I., Choat, J. H. (1987). Estimating total abundance of a large temperate-reef fish using visual strip transects. Mar. Biol. 96: 469-478

Molles, M. C. (1978). Fish species diversity on model and natural reef patches: experimental insular biogeography Ecol. Monogr. 48: 289-305

Munro, J. L. (1983). Epilogue: progress in coral reef fisheries research, 1973-1982. In: Munro, J. L. (ed.) Caribbean coral reef fishery resources. ICLARM Studies and Reviews 7 Manilla, p. 249-265

Ogden, J. C., Ehrlich, P. R. (1977). The behaviour of heterotrypic resting schools of juvenile grunts (Pomadasyidae). Mar. Biol. 42: 273--280

Russ, G. R. (1985). Effects of protective management on coral reef fishes in the central Philippines. Proc. 5th Int. Coral Reef Symp. 4: 219-224

Russell, B. C., Anderson, G. R. V., Talbot, F. H. (1977). Seasonality and recruitment of coral reef fishes. Aust. J. mar. Freshwat. Res. 28: 521-528

Russell, B. C., Talbot, F. H., Anderson, G. R. V., Goldman, B. (1978). Collection and sampling of reef fishes. In: Stoddart, D. R., Johannes, R. E. (eds.) Monographs on oceanographic methodology, Vol 5, Coral reefs: research methods UNESCO, Norwich, p. 329-345

Sale, P. F. (1980a). The ecology of fishes on coral reefs Oceanogr. mar. Biol. A. Rev. 18: 367-421

Sale, P. F. (1980b). Assemblages of fish on patch reefs - 
predictable or unpredictable? Environ. Biol. Fish. 5: 243-249

Sale, P. F., Douglas, W. A. (1981). Precision and accuracy of visual census technique for fish assemblages on coral patch reefs. Environ. Biol. Fish. 6 (3/4): 333-339

Sale, P. F., Douglas, W. A. (1984). Temporal variability in the community structure of fish on coral patch reefs and the relation of community structure to reef structure. Ecology 65: $409-422$

Sale, P. F., Sharp, B. J. (1983). Correction for bias in visual transect censuses of coral reef fishes. Coral Reefs 3 : $37-42$

Sale, P. F., Steel, W J. (1986). Random placement and the distribution of fishes among coral patch reefs. Mar. Ecol. Prog. Ser. 28: 165-174

Samoilys, M. A. (1989). Abundance and species richness of coral reef fish on the Kenyan Coast: the effects of protective management and fishing. Proc. 6th Int. Coral Reef Symp. 2: 261-266

Shulman, M. J., Ogden, J. C. (1987). What controls tropical reef fish populations: recruitment or benthic mortality. An

This article was presented by Dr D. KJumpp, Townsville, Australia example in the Caribbean reef fish Haenulon flavolineatum. Mar Ecol. Prog. Ser 39: 233-242

Sokal, R. R., Rohlf, F. J. (1981). Biometry, 2nd edn. W. H. Freemann and Co., New York

Thresher, R. E. (1983). Environmental correlates of the distribution of planktivorous fishes in the One Tree Reef Lagoon. Mar Ecol. Prog. Ser. 10: 137-145

Thresher, R. E., Gunn, J. S. (1986). Comparative analysis of visual census techniques for highly mobile, reef-associated piscivores (Carangidae). Environ. Biol. Fish. 17 (2): 93-116

Underwoad, A. J. (1981). Techniques of analysis of variance in experimental marine biology and ecology. Oceanogr. mar. Biol. A. Rev. 9: 513-605

Werner, E. E., Gilliam, J. F. (1984). The ontogenetic niche and species interactions in size structured populations. Ann. Rev. Ecol. Syst. 15: 393-425

Williams, D. McB. (1980). Dynamics of the pomacentrid community on small patch reefs in One Tree Lagoon (Great Barrier Reef). Bull. mar. Sci. 30: 159-1.70

Winer, B. J. (1971). Statistical principles in experimental design. McGraw-Hill Inc., New York

Manuscript first received: October 20,1989

Revised version accepted: March 30, 1990 